\title{
The Parenting Task: Parents' concerns and where they would seek help
}

\author{
Jane Akister \\ Ken Johnson
}

Address for correspondence:

Jane Akister, School of Social and Community Studies, Anglia Polytechnic University, East Road, Cambridge CB1 1PT. United Kingdom

Tel: 01223363271

E mail: j.akister@apu.ac.uk

The authors wish to express thanks to Parentline Plus and Anglia Polytechnic University for their sponsorship and to the Young Parents Project for their involvement in the research. 


\begin{abstract}
Governments are concerned to promote positive parenting but it is difficult to know how and where to target the necessary support. How should we listen to the concerns expressed by parents themselves? Social work and health care professionals and those involved in developing parenting programmes tend to base their interventions on their experiences with families already in crisis. This paper reports on a survey of the views of two groups of parents: a community sample and a small group of parents involved in a young parents' project. Issues, which concern the parents, are identified as well as consideration of which agencies might be best placed to address these. Parents were most likely to approach their children's school or doctor for information, advice or support. Parents were found to be reluctant to approach social work agencies.
\end{abstract}

KEY WORDS: Parenting, family, supporting young parents 


\section{INTRODUCTION}

Good parenting benefits us all. It provides children with the best possible start in life. It improves their health, schooling and prospects in later life, and it reduces the risk of serious social problems such as truancy, offending and drug misuse.

(Her Majesty’s Stationery Office, 1998: 1.1).

Stresses on the family make it increasingly difficult for vulnerable parents to meet all their children's needs. A range of initiatives is needed to improve parenting skills, from education in schools, to support for new parents and practical help for parents in difficulties. Some government initiatives have been started in these areas and are to be welcomed. However there are still important gaps and insufficient focus on mental health needs.

(Mental Health Foundation, 1999, Findings).

Parenting is a complex task with increasing expectations being placed on parents. We were interested to explore parents' concerns and to consider whether or not they are a good barometer for problems which need responding to. We also wanted to know whether parents think that parenting is something which can be learnt and to what extent they felt supported in the parenting task. We felt that this would give an indication of the 'openness' of parents to the idea of seeking and accepting assistance with the parenting task.

Firth et al. state that clinical and service evaluation often fails to accommodate sufficiently to parental perspectives and priorities concerning health interventions. Although parent satisfaction questionnaires are widely used, these assess issues chosen by the researcher. (Firth et al., 2000). The first question we were interested in was how accurate are parents' concerns over a range of social and developmental issues. The second question was whether services provided meet the concerns of parents or only those concerns identified by service providers. The third question is what service providers do parents find acceptable?

In relation to the accuracy of parents concerns, could parents' concerns be used as a screening measure, to aid in making focused referral decisions or to help target families for developmental promotion? A number of studies have looked at this in relation to specific issues. In relation to their child's developmental progress, there is evidence to suggest that parents are accurate in their concerns. Glascoe, in a study of families with children under 7 years of age, reports that if systematically elicited parents' concerns about children's development approach standards for screening tests and can be used to make reasonably accurate referral decisions (Glascoe, 1997). Prochazkova's study of developmental changes in a group of Czech infants also report agreement between parent and professional ratings (Prochazkova, 1997). In a different study, Glascoe, looking at identifying children with disability in the pre-school years, found parent's concerns were as accurate as quality screening tests and facilitated an evidence-based approach to decisions about children's developmental needs (Glascoe, 2000). 
When looking at areas other than their child's developmental progress, researchers have found that social and environmental factors may lead to overconcern or a lack of information being reported by parents. A study on a housing estate in Leeds with many environmental hazards, such as 'drug-users', 'strangers' and litter, looked at parents' concerns as to their children's safety in public places. It found that parent's anxieties were leading to excessive surveillance of their children, placing a psychological strain on the parents (Dixey, 1999). Looking at parents' concerns in relation to drugs, a survey showed that parents are concerned about drugs and their availability in relation to their children but are largely misinformed about the drug situation and need accurate and up-to-date information to enable appropriate responses (Mallick et al. 1998).

Health providers have identified that, when parents present at health clinics with their children, there is a group who are over anxious in relation to the problem presented. A study of parental anxiety, in relation to minor illness in their children, found that high anxiety levels were related to factors beyond the child's presenting condition, including finances, relationships and employment (Richtsmeier \& Hatcher, 1994). This resonates with an American study which discusses the high rate of behavioural, developmental, and psychosocial problems that are presented in health care settings (Menahin and Lipton, 1998). While policy makers emphasise the importance of offering children and their parents guidance and support, the best way to provide this and the best settings remain unclear.

The second question, of whether services provided meet the concerns of parents or only those concerns identified by service providers, was researched in a study of parents with disability (Llwewellyn et al. 1998). This study looked at whether services being provided were responsive to parent-identified concerns since these may differ from the concerns of service workers, family members and friends. They found significant differences in the concerns of parents and professionals. The parents identified gaps in relation to involvement in the community such as how to meet people and make friends, while workers were focussing solely on the child care issues (Llwewellyn et al. 1998). Parental well-being is, of course, crucial to the long-term outcomes for their children and therefore important to address.

Thus, studies accessing a range of different areas of family life have found that the concerns expressed by parents are accurate and need to be considered. Parents may be overconcerned, sometimes through a lack of knowledge, and this would also need to be identified. The third question of how to meet these needs, and through what service providers is problematic especially when families present in settings designed to deal with other issues. Some parents are reluctant to use certain services. Attride-Stirling et al. (2001) looked at what puts people off using services which are designed to promote psychosocial well-being. Disincentives included inability to trust professionals due to bad past experiences, professionals' lack of communication skills and inaccessibility due to location and appointment times.

In our study we seek parents' views, in the community and in a young parents' project, about their main concerns in their task as parents, where they would go to seek help and what they would be looking for. We also looked at whether they thought that parenting was a skill which could be learnt. 


\section{METHOD}

The purpose of this study was to give young parents, involved in a project for teenage mothers, an opportunity to identify areas that concern them in the parenting task and to explore whether they thought that parenting can be learned. We were also looking at where or what agencies they would approach for help and what kind of help they would find acceptable. For a comparison group we selected a sub-sample from a community study, also with young children.

\section{Sample}

These results are based on two samples. A community sample and a sample of parents involved in a Young Parents' Project (YPP). The community sample $(n=55)$ were volunteers, for this project, from a larger community study (Akister \& Johnson, 2002). A sub-sample of 20 was selected from this group to exclude parents with older children (11 years and over). This was in order to focus on the needs of parents with infants and young children as none of the YPP parents had older children.

The YPP is a supported living project run by social work and social care staff for mothers aged 15-19; the residents are all identified as 'at risk' in the parenting task. Eight YPP parents volunteered for this study. Although this is a small group numerically it represents $40 \%$ of the project users. We are reporting on these groups together as the YPP findings give some indication of the potential of small locally based projects for supporting parents.

The age of the parents ranged from a father aged 45 to a mother aged 17, with the bulk of the respondents from the community sample being in the 30-40 age range and from the YPP in the 17-20 age range. Respondents were asked to describe their ethnic origin. All subjects described themselves as British, including 2 describing themselves as Black British and one as Chinese British. One parent reported themselves as having a disability; no parents reported their children as having a disability.

\section{Procedures}

The study received ethical approval from the university ethics panel. A letter was sent to parents from their school or from the YPP inviting them to participate in the study. The letter described the study and included an information sheet for participants, a consent form and a self-administered questionnaire. Parents were also informed that copies of the report on the study would be available to them through the YPP or school. The response rate was $40 \%$ for the YPP and $42 \%$ from the school.

\section{Instruments}

The questionnaire was structured but also gave some opportunities for parents to add their views. The questionnaire was piloted in a local school. The first section asked parents to identify their living arrangements, whether or not they felt supported in the task of parenting and their ideas about whether parenting was a skill, which they thought could be learned. The second section explored potential sources for material on parenting using the internet as an example and looked at what parents were wanting: advice, information or support. It then asked them to consider areas which concerned them and to identify where they thought they would go for such help, for example, family only, family and friends or outside their social networks. Where the responses are qualitative these have been categorised. The categories are not robust enough for comparative statistics. 


\section{RESULTS}

\section{Where the results for the Community sample and the YPP are significantly different these are reported separately. Otherwise results are presented for the whole cohort.}

\section{Can parenting be learned?}

All the parents thought that parenting is a skill which can be learned, with $75 \%$ indicating that their own parents were the best placed to teach these skills. They also thought that skills could be learned in parenting groups (79\%) or at school (43\%). These responses indicate an openness to the idea of seeking \&/or accepting help in situations of difficulty or uncertainty with parenting issues.

\section{Do parents feel supported in their role as parents?}

Family living arrangements are shown in Table 1 and show that 35\% of the community sample and the entire YPP sample were not living with the child's other natural parent.

Table 1 here.

Did the respondent feel supported by the children's other natural parent in the parenting role? Of those in the community sample who felt supported by the other natural parent (65\%), all except one were living together. In the YPP sample 2 parents felt supported by the other natural parent and none were living together. Thus for those living apart from the other natural parent all except three felt unsupported by them. While this finding may be unsurprising, it is depressing to discover that there is still such a lack of support, from each other, experienced by separated parents in the community as a whole.

We were also interested in how supported they felt as parents 'from all sources'. This question was open-ended and the replies categorised. Although 93\% had said that they had family and friends who they could talk openly to about parenting, only 84\% felt supported in their role as 'parent'. This leaves 16\% reporting that they feel unsupported as parents although, when asked where they would go for support, this reduces to $10 \%$ who report having nowhere to go (see Table 2). The parents who felt unsupported were all in the community sample and represent a significant number of parents feeling isolated in the parenting task. It is encouraging for the YPP that all these parents felt supported, largely by the YPP project.

\section{Table 2 here}

In the main parents turn, for support, to family and friends (70\%, see Table 2) and in the case of the YPP parents, to the project. Also of note here are the other sources of support cited. Of the two parents in the Community sample who indicated an outside agency, one indicated their GP and one their child's school. Parents from the YPP rely heavily on the project for support.

\section{Do parents think that the Internet or social services can offer information, advice and support?}


Although only one parent had looked up parenting on the Internet 82\% thought it would be a useful resource and would be able to offer information (82\%), advice (47\%) and support (16\%). Considering how few have actually looked up parenting on the Internet these replies are quite remarkable. They confirm that parents are often seeking information and that perhaps the anonymity and control offered by the Internet would make it an acceptable route for parents.

In relation to Social Services, 32\% thought that social services would be an appropriate place to approach for issues to do with parenting. However when asked to identify specific issues and where they would go for help only $14 \%$ thought that they would actually go to social services.

The questions relating to the Internet and social services were, in part, designed to introduce the concept of resources which could offer help to parents prior to asking them where they might go for help.

\section{What issues most concern parents?}

Parents were asked to select the three issues (from a list of thirteen) that they thought most concern parents. The results are shown in Table 3.

Insert Table 3 here.

The four issues, which most concerned parents in our community sample, were: behaviour management (80\%), school bullying (55\%), alcohol and drug misuse (45\%) and child abuse (30\%). These findings are similar to those of an earlier study (Akister \& Johnson, 2002).

In the YPP sample, issues relating to infant care (63\%) and child abuse (63\%) come into the top four concerns along with family relationships (50\%) and alcohol and drug misuse (38\%). The concerns about infant care probably relate to their experience as first time mothers. The concerns about child abuse initially seem unsurprising in a group identified as vulnerable and in need of support. Further research is needed to identify what this means and whether they are concerned that they, or other people, might abuse their child.

\section{Where do parents go for help?}

This was a completely open question although parentline, family and friends, the Internet and social services will have been suggested by the nature of the previous questions. (The questions in relation to these services were intentional to stimulate thought about a broad range of possible types of help). In the community sample the key destinations quoted were: School (55\%), Family \& Friends (50\%), Health Providers (30\%), Police (5\%), Social Services (10\%). Only one parent reported that they would use a telephone helpline.

In terms of seeking help outside personal networks, the school or health services are the most likely destination. Since neither of these agencies had been suggested by the previous questions this is an important finding. Why, having reported that they think social services could offer information, advice and support, would parents not go 
there? There are important policy issues here in the delivery of acceptable support for parents.

In relation to the YPP, seven of the eight parents would use the project workers. Four would also use health providers or family and friends and one would use the police and one social services. Again, considering that these families have all had experience of social services, they are reluctant to turn to them except for financial assistance.

\section{What response are parents looking for when seeking help?}

Parents when seeking help reported that they would be looking for: Support (71\%); Advice (57\%); Action (21\%); Information (21\%).

The response of 'Action' is largely in relation to school bullying. (In the case of the one YPP parent action was wanted in relation to child abuse.) School bullying is in quite a different category to the other issues, with parents wanting it sorted out and having a clear view of the solution. All the other issues of major concern have elements of choice of intervention, as with behaviour problems, and parents are seeking support and advice as to how to deal with these.

\section{DISCUSSION}

Parents of children of all ages are concerned about issues to do with behaviour management, family relationships, alcohol and drug misuse and school bullying (Akister \& Johnson, 2000 \& 2002). These are also the issues, which concern those professionals charged with working with children and supporting families. In line with other studies of 'parents' concerns' we find that parents are able to identify concerns and that these will need addressing in the setting in which they are raised (Prochazkova et al, 1997; Glascoe, 1997). In relation to concerns about drugs and alcohol, Mallik et al., 1998 have demonstrated the need for information and this is an issue, which is clearly of major concern to parents in our study.

In relation to school bullying, 'Action' is sought. This is clearly an expectation from the school setting. In relation to the other main concerns, parents are most likely to approach the school or their doctor or health visitor. We suggest that this is because these settings are seen as helpful environments concerned to promote their child's well being and progress. We will examine this idea further in our next study.

The settings which are perceived as the potential sources for the advice, support and information which parents are seeking are the settings which need developing as centres to deal with parents' concerns, if only as a referral point to appropriate services. If parents are unable to satisfy their concerns these will either develop into overanxieties, which puts psychological strain on the parents (Dixey, 1999) or the unaddressed concerns, for example, about behaviour or child abuse may escalate to more serious problems.

The use of telephone helplines has been proposed as a source of support for parents. As part of an UK government initiative to support parents a new national parenting helpline developed by Parentline Plus has been set up in the UK to: “..offer advice to parents and refer people to local sources of help.” (HMSO, 1998: 1.4). There is a place for this service but its potential should not be overestimated since many parents 
want to use the institutions or professionals that already know and work with their child and who they feel have their child's interests at heart.

Sawatsky \& Pare, 1996, suggest that the two powerful systems of family and school are too often isolated from each other when it comes to the welfare of the child experiencing difficulties. They propose a process whereby school counsellors can facilitate family-school meetings as a means of reducing the segregation. Their suggestion is in line with the views expressed by the parents in our study who would use school and health providers as their agency of choice.

Is there a place here for social work agencies? Parents do not wish to approach social services and, indeed, social services, in the main, target their efforts towards families already identified as having major difficulties. However, social work agencies have a potential role, along with schools and health providers, in supporting parents and families in the community in their task as parents. This may need to be through a redesigned service to remove the stigma and fear associated with the present services or it may need to be through interagency working between educational, health and social service professionals. The YPP is run by a qualified social worker, and is perceived as highly supportive despite at times having to be involved in recommending that, for its protection, a child is removed from their parents care. Our research with Home-Start also indicated that parents find locally-based parenting projects helpful and acceptable (Akister \& Johnson, 2003). These findings support those of other researchers in relation to the importance of accessibility of services to users (Attride-Stirling et al., 2001).

In conclusion it seems vital to listen to parents concerns and find settings which are acceptable to parents to promote positive child care outcomes for families. Parents can identify their concerns and are suggesting utilising agencies where they and their child are already known and have a relationship with the service providers. Clearly this may mean introducing other professionals into these settings to facilitate these developments and is in line with current trends towards multi-agency provisions to promote child care and family well-being. 


\section{$\underline{\text { References }}$}

Akister, J \& Johnson, K. (2000). Issues Which Concern Young Parents. Report for Young Parents Project, APU Publications.

Akister, J \& Johnson, K. (2002). Parenting Issues Which May be Addressed Through a Confidential Helpline. Health \& Social Care 10(2), 106-11.

Akister, J. \& Johnson, K. (2003). Parenting with Home-Start: Users' views. Practice, 15(1), 21-32.

Attride-Stirling, J., Davis,H., Markless, G., Sclare, I. \& Day, C. (2001). Someone to Talk to Who'll Listen: Addressing the psychosocial needs of Children and Families. Journal of Community and Applied Psychology, 11(3), 179-191.

Dixey, R. (1999). Keeping Children Safe: The effect on parent's daily lives and psychological well-being. Journal of Health Psychology, 4(1), 45-57.

Firth, H., Grimes, A., Poppleton, H., Hall, R. \& Richold, P. (2000). Assessment of Parents' Concerns and Evaluation of Outcomes. Journal of Public Health Medicine, 22(4), 473-8.

Glascoe F.P. (1997). Parents concerns about their children's development: Prescreening technique or screening test? Pediatrics, 99(4), 522-8.

Glascoe, F.P. (2000). Evidence-Based Approach to Developmental and Behavioral Surveillance Using Parent's Concerns. Child: Care, Health \& Development, 26(2) 137-149.

Her Majesty’s Stationery Office (1998). Supporting Families: A Consultation Document. http://www.homeoffice.gov.uk/vcu/suppfam.htm

Llwewllyn, G., McConnell, D. \& Bye, R. (1998). Perceptions of Service Needs by Parents with Intellectual Disability, their Significant Others and their Service Workers. Research in Developmental Disabilities, 19(3), 245-260.

Mallick, J., Evans, R. \& Stein, G. (1998). Parents and Drug Education: Parents concerns, attitudes and needs. Drugs: Education, Prevention \& Policy, 5(2), 169176.

Menahem, S. \& Lipton, G.I. (1998). The Pediatrician as Therapist I: Psychoanalytic psychotherapy. Journal of Developmental and Behavioral Pediatrics, 19(2), 101104.

Mental Health Foundation. (1999). Bright Futures.

http://www.mentalhealth.org.uk/peer/brightfutures.htm 
Prochazkova, E., Brichacek, V., Drittrichova, J, Sobotkava, D. \& Vondracek, J. (1997). Parent's Concerns Regarding Infant Development: Kent Infant Development (KID) Scale. Studia Psychologica, 39(4), 263-265.

Richtsmeier, A.J. \& Hatcher, J.W. (1994). Parental Anxiety and Minor Illness. Journal of Developmental and Behavioral Pediatrics, 15(1), 14-19.

Sawatzky D. \& Pare, D. (1996). Expanding the conversation: Family-school collaboration. Canadian-Journal-of-Counselling, 30(4): 228-239. 
TABLE 1. Family Living Arrangements

\begin{tabular}{|c|c|c|c|c|}
\hline & \multicolumn{2}{|c|}{ Community } & \multicolumn{2}{|l|}{ YPP } \\
\hline & $\mathrm{n}=20$ & $\%$ & $\mathrm{n}=8$ & $\%$ \\
\hline Living with children's other natural parent & $13 *$ & 65 & 0 & 0 \\
\hline Single parent with support from other natural parent & 2 & 10 & 4 & 50 \\
\hline Single parent without support from other natural parent & 2 & 10 & 3 & 37 \\
\hline With a new partner & 3 & 15 & 0 & 0 \\
\hline Other - please explain & 0 & 0 & 1 & 12 \\
\hline
\end{tabular}

Note. $*=$ Fishers Exact Test, $\mathrm{p}<0.005$, living with natural parents compared with all other arrangements. 
TABLE 2. Sources of support for parents

\begin{tabular}{lccccc}
\hline & \multicolumn{2}{c}{ Community } & \multicolumn{2}{c}{ YPP } \\
\cline { 2 - 6 } & & & & \\
& $n=20$ & $\%$ & & \\
& & & & & \\
& 14 & 70 & & 3 & 37 \\
Family \& friends & 4 & 20 & 0 & 0 \\
School \& Health & 2 & 10 & 0 & 0 \\
No support & $\mathrm{n} / \mathrm{a}$ & & 5 & 63 \\
Project (YPP) & & & & & \\
\hline
\end{tabular}


TABLE 3. Issues that concern parents

\begin{tabular}{|c|c|c|c|c|}
\hline & \multicolumn{2}{|c|}{ Community } & \multicolumn{2}{|c|}{ YPP } \\
\hline & $\mathrm{n}=20$ & $\%$ & $\mathrm{n}=8$ & $\%$ \\
\hline Behaviour Management & 16 & $80 * 1$ & 2 & 25 \\
\hline School Bullying & 11 & 55 & 2 & 25 \\
\hline Alcohol and Drug Misuse & 9 & 45 & 3 & 37 \\
\hline Child Abuse & 6 & 30 & 5 & 63 \\
\hline Family Relationships & 4 & 20 & 4 & 50 \\
\hline Infant Care & 3 & $15 *^{2}$ & 5 & 63 \\
\hline Teenage Sexuality & 3 & 15 & 5 & 63 \\
\hline Mental Health & 2 & 10 & 0 & 0 \\
\hline Parental Disagreements & 2 & 10 & 1 & 12 \\
\hline Racial Intolerance & 1 & 5 & 0 & 0 \\
\hline Custody/Access & 0 & 0 & 1 & 12 \\
\hline Other - please specify & 1 & 5 & 0 & 0 \\
\hline
\end{tabular}

Note. Fishers Exact Test: ${ }^{*} \mathrm{p}=0.001 ;{ }^{*}{ }^{2} \mathrm{p}=0.02$ 